\title{
The Prestretching Effect on the Force Decay of Orthodontic Elastic Chain
}

\author{
${ }^{1}$ Adelson Mota de Aguiar, ${ }^{2}$ Arilton Mota de Aguiar, ${ }^{3}$ Júlio de Araújo Gurgel, ${ }^{4}$ Celia Regina Maio Pinzan Vercelino \\ ${ }^{5}$ Etevaldo Matos Maia Filho, ${ }^{6}$ Matheus Coelho Bandeca, ${ }^{7}$ Rudys Rodolfo de Jesus Tavarez
}

\begin{abstract}
This in vitro study evaluated the influence of prestretching, in the force decay of orthodontic elastic chains, at three time intervals: 2, 7 and 30 days with the brands Morelli, Orthometric and American Orthodontics. In the experimental group, prestretching was performed, stretching the elastics to increase them by $50 \%$ of their original length three times in a quick and sequential mode. All of the elastic chains were kept stretched and stored in artificial saliva at $37^{\circ} \mathrm{C}$ until the time of force measurement. For comparisons between the control and experimental groups, the Mann-Whitney test was used. For comparisons between time points and brands, the Kruskal-Wallis test was used, and for multiple comparisons, Miller's post-hoc test was used. The results showed statistically significant differences among the different commercial brands tested at the initial time point. The mean force at the initial time point ranged from 2.57 to $3.17 \mathrm{~N}$. By day 2, the force values were between 0.97 and $1.49 \mathrm{~N}$; by day 7 , the values were 0.56 and $0.94 \mathrm{~N}$. By day 30 , the force values ranged between 0.27 and $0.66 \mathrm{~N}$. We concluded that performing and duration of prestretching and the brand all influenced the force decay of orthodontic elastic chains. Time had a greater influence on the decay of the elastics than brand or prestretching.
\end{abstract}

Keywords: Orthodontics, Elastomers, Tooth movement, Orthodontic space closure.

How to cite this article: de Aguiar AM, de Aguiar AM, de Araújo Gurgel J, Vercelino CRMP, Filho EMM, Bandeca MC, de Jesus Tavarez RR. The Prestretching Effect on the Force Decay of Orthodontic Elastic Chain. J Contemp Dent Pract 2014;15(4):456-460.

\section{Source of support: Nil}

Conflict of interest: None declared

\section{INTRODUCTION}

The orthodontic elastic chain has significant use in orthodontic procedures due to its versatility. It consists of

\footnotetext{
${ }^{1,2}$ Postgraduate Student, ${ }^{3-7}$ Professor

${ }^{1-7}$ Department of Postgraduate Dentistry, CEUMA University São Luis, Maranhão, Brazil
}

Corresponding Author: Rudys Rodolfo de Jesus Tavarez Professor, Department of Postgraduate Dentistry, Avenida dos Holandeses No. 07, Edificio Metropolitam, Calhau, São Luis Maranhão, Brazil, CEP: 65071-380, Phone: (55)9832272360 e-mail: rudysd@uol.com.br amorphous polymers made of polyurethane $\mathrm{e}^{1,2}$ and has been used in orthodontics since 1960. ${ }^{1,3}$ Currently, it is routinely used in different modalities of orthodontic mechanics.

Orthodontic elastic chains can be used in clinical practice to conjugate teeth, rotation correction, for diastema and spaces closure. ${ }^{1,2,4-7}$ They are readily available, are low cost, do not require patient co-operation for their use, are available in different sizes and colors and are easy to use in clinical applications. ${ }^{4}$

However, there are disadvantages to their use, including color change, plastic deformation, ${ }^{4}$ retention of biofilms and especially the continuing deterioration of their force during use, ${ }^{2,8-10}$ which impairs the quality of the orthodontic mechanics in addition to the manifest initial decay of strength. ${ }^{1,5,8,11}$

For this reason, some studies have recommended the prestretching of the elastic before use. ${ }^{2,8,11}$ It consists of stretching the elastic before using it to minimize the effect of abrupt force decay in the first hours of use. ${ }^{5}$ However, studies have not found significant effects from this procedure. Brantley and collaborators did not obtain satisfactory result regarding the prestretching of elastic chains. ${ }^{7}$ Kim et al also found no significant difference when comparing the prestretched and unprestretched elastics groups. ${ }^{12}$

One of the issues raised is that prestretching could produce the beneficial effect of maintaining a more constant force. Another is that this procedure could further decay the force exerted by the elastic during use by causing permanent deformation of the elastic. ${ }^{4}$

The aim of this study was to evaluate the influence of prestretching on the decay of the force of orthodontic elastic chains.

\section{MATERIALS AND METHODS}

Ten specimens of elastic chains from three different companies were including in this study: American Orthodontics (Sheboygan, Wisconsin, USA); Orthometric (Beijing, China) and Morelli (Sorocaba, São Paulo, Brazil). The elastics were cut into pieces with five bonds. During the experiment, the elastic brands were randomly represented by the numbers 1,2 and 3 without the knowledge of the operator. 
The specimens of each brand were divided into control and experimental groups (Flowchart 1). The experimental groups were prestretched with three stretchings of the elastic chain segment in a quick and sequential manner with a Palmer stapling pliers (Jon Comércio de Produtos Odontológicos, São Paulo, Brazil). The pliers was set to limit the maximum opening to $21 \mathrm{~mm}$ because that distance represented an increase of $50 \%$ of the initial length of the sample. To avoid deformation of the elastic after returning from prestretching, the minimum opening was set to $14 \mathrm{~mm}$ were determined.

To store the specimens, acrylic plates were made in which two parallel rows of equidistant metal pins in rows that were $22 \mathrm{~mm}$ apart were fixed (Fig. 1). This distance was selected, because it represents the average distance of the upper first molar to the upper canine. ${ }^{18}$ The elastics were placed in that plate and held stretched during the time of this study (2, 7 and 30 days). The acrylic plates were immersed in artificial saliva (Farmacopa Farmácia Ltda, Rio de Janeiro, Brazil) and stored in a bacteriological incubator (Bio Par Equipamentos Eletro Eletrônicos, Porto Alegre, Rio Grande do Sul, Brazil) at $37^{\circ} \mathrm{C} \pm 1{ }^{\circ} \mathrm{C}$.

The elastic forces were measured at the following time points: initial (not stored in artificial saliva), and after 2, 7 and 30 days of prestretching. All of the measurements were made by a single operator using a dynamometer DD 500 (Instrutherm Ltda, São Paulo, Brazil) with the support adapted for testing (Fig. 2).
The transference of the elastics from the acrylic plates to the dynamometer was performed using a Palmer clasping forceps (Golgran Indústria e Comércio de Instrumental Odontológico, São Caetano do Sul, São Paulo), which was prepared to have a fixed opening equivalent to $22 \mathrm{~mm}$ in length to avoid modifying the length of the elastic during the transfer for measurement. After positioning the elastic chain in the dynamometer, all of the samples were allowed to rest for 10 seconds to obtain stability of the result of the measured force.

The data were subjected to analysis of variance according to three criteria: brand, prestretching and time; however, the analysis did not demonstrate homogeneity of the variances as evaluated by the Bartlett test. Thus, nonparametric tests were chosen because they have no restrictions regarding the distribution of the groups. For comparisons between the control and experimental groups, the Mann-Whitney test was used. For comparisons among the four time points and the three brands, the Kruskal-Wallis test was used. And for multiple comparisons, Miller's post-hoc test was used. In this study, a significance level of $5 \%$ was used for all of the tests.

\section{RESULTS}

The mean values and standard deviations of the studied groups are shown in Table 1. All of the specimens showed similar behavior in the decay of the forces during the testing period (Graph 1).

Flowchart 1: Experimental design
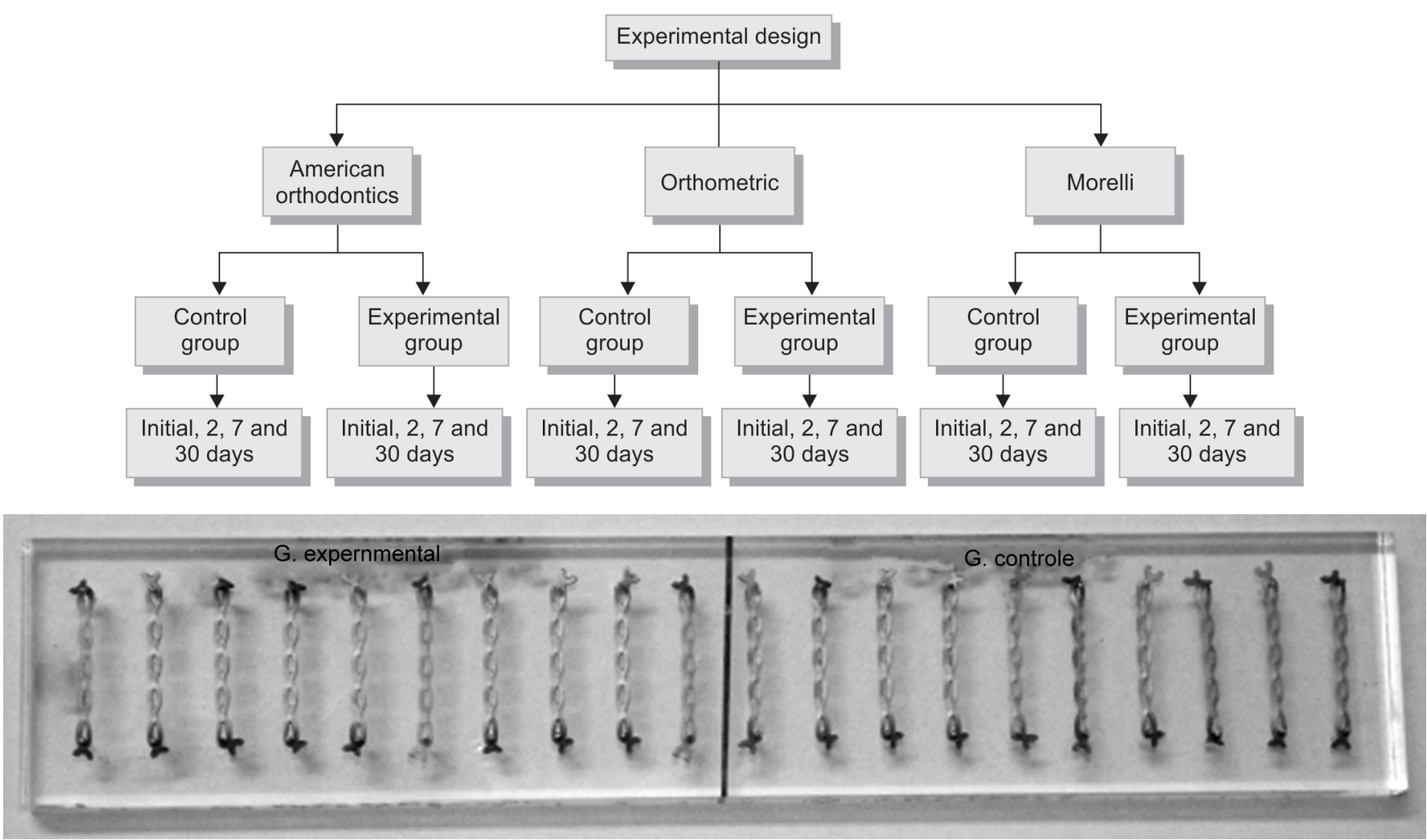

Fig. 1: Specimens in a position on acrylic plates 


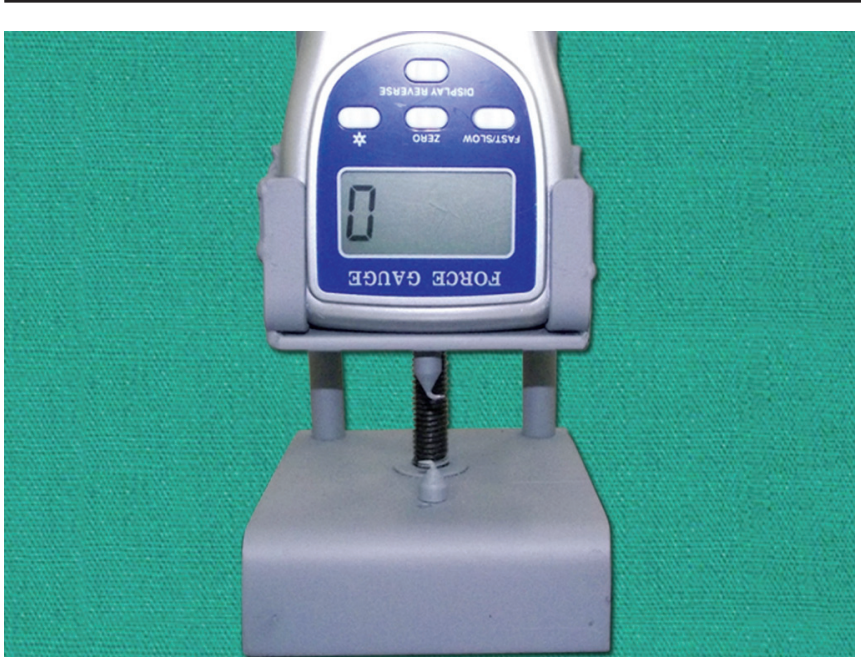

Fig. 2: Dynamometer in position to perform the tests

In the initial period, there was a statistically significant difference among the three brands when comparing the control and experimental groups with the highest force values observed in the experimental groups. In addition to during the initial period, the American Orthodontics and Morelli brands showed statistically significant differences at 7 days, and the Orthometric brand showed a statistically significant difference at 30 days (Table 1).

No statistically significant differences were observed between the following intervals for any of the tested brands in both the control and experimental groups: initial and 2 days, 2 and 7 days, or 7 and 30 days. A significant difference was observed for all of the groups between the initial time and at 7 and 30 days and between 2 days and 30 days (see Table 1).

Comparing the force decay of the elastics among the control groups for the three brands, there was statistically significant difference for the American Orthodontics compared with the other two brands at the initial time point as well as for the Orthometric brand compared with the other brands at 2 and 7 days. Finally, there was a statistically significant difference among the three brands at 30 days.

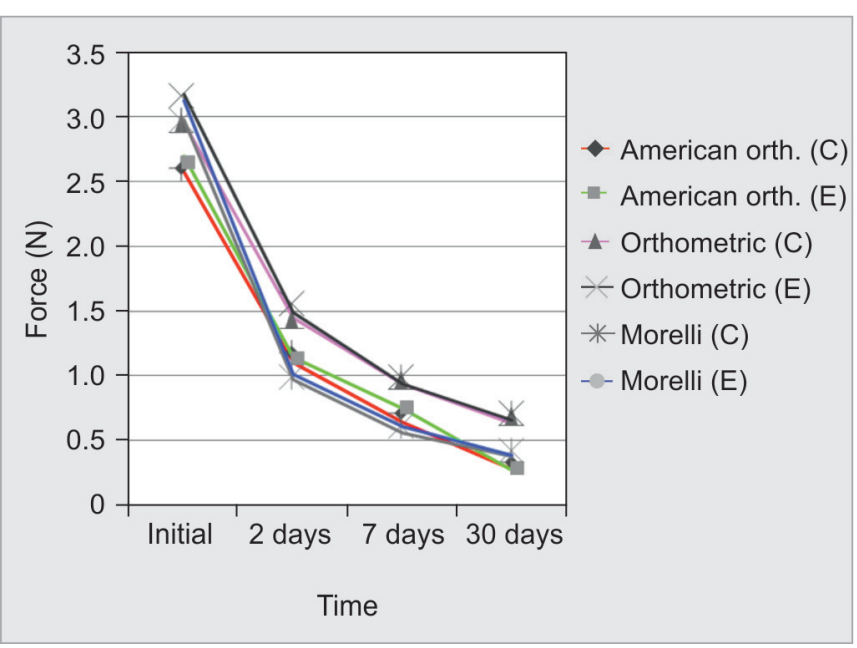

Graph 1: Behavior of the orthodontic elastic chains during the different time intervals of testing

Comparing the decay of the forces among the experimental groups, the American Orthodontics brand showed a statistically significant difference compared with the other brands at the initial time point. For Morelli, there was a statistically significant difference compared with the other brands at 7 days. Finally, there were statistically significant differences among the three brands at 2 and 30 days (Table 2).

\section{DISCUSSION}

Understanding the behavior of elastic chains during orthodontic mechanics and their performance with respect to prestretching is essential to adapt their use to clinical orthodontic needs. Thus, a more favorable result can be achieved by decreasing the undesirable aspect of strong decay of the initial force. The findings of this study demonstrated a statistically significant difference among the groups regarding prestretching of the elastics brands, rejecting the hypothesis formulated for these items generally although accepting it regarding time because this was the factor that most influenced elastic decay.

Table 1: Comparison of force degradation of orthodontic elastic chains in each tested brand in the control (C) and experimental $(E)$ groups

\begin{tabular}{|c|c|c|c|c|c|c|c|c|c|}
\hline \multirow[t]{2}{*}{ Brands } & \multirow[t]{2}{*}{ Groups } & \multicolumn{2}{|c|}{ Initial } & \multicolumn{2}{|c|}{ Day 2} & \multicolumn{2}{|c|}{ Day 7} & \multicolumn{2}{|c|}{ Day 30} \\
\hline & & Mean & $S D$ & Mean & $S D$ & Mean & $S D$ & Mean & $S D$ \\
\hline \multirow{3}{*}{$\begin{array}{l}\text { American } \\
\text { orthodontics }\end{array}$} & $\mathrm{C}$ & $2.57^{a}$ & 9.9 & $1.10^{a b}$ & 11.6 & $0.64 b c$ & 15.4 & $0.28^{c}$ & 3.8 \\
\hline & E & $2.70^{a}$ & 8.2 & $1.14 \mathrm{ab}$ & 3.5 & $0.75^{b c}$ & 13.4 & $0.27^{c}$ & 3.0 \\
\hline & & $0.007^{*}$ & & 0.684 & & $0.023^{*}$ & & 0.123 & \\
\hline \multirow[t]{3}{*}{ Orthometric } & $\mathrm{C}$ & $2.95^{a}$ & 10.6 & $1.45^{a b}$ & 4.2 & $0.94 b c$ & 14.7 & $0.63^{c}$ & 3.8 \\
\hline & E & $3.17^{a}$ & 11.9 & $1.49 a b$ & 5.4 & $0.94 b c$ & 16.2 & $0.66^{c}$ & 2.1 \\
\hline & & $0.001^{*}$ & & 0.123 & & 0.971 & & $0.043^{*}$ & \\
\hline \multirow[t]{3}{*}{ Morelli } & C & $2.98^{a}$ & 8.5 & $0.97 \mathrm{ab}$ & 4.3 & $0.56^{b c}$ & 4.4 & $0.38^{c}$ & 2.1 \\
\hline & $E$ & $3.12^{\mathrm{a}}$ & 10.9 & $1.01 \mathrm{ab}$ & 5.0 & $0.61 b c$ & 2.3 & $0.39^{c}$ & 4.6 \\
\hline & & $0.003^{*}$ & & 0.105 & & $0.019^{*}$ & & 0.353 & \\
\hline
\end{tabular}

* Statistically significant difference $(p<0.05)$; time points with the same superscript letter do not present statistically significant differences between them 
Table 2: Comparison of force degradation of orthodontic elastic chains among the tested brands in the control (C) and experimental $(E)$ groups

\begin{tabular}{|c|c|c|c|c|c|c|c|c|c|}
\hline \multirow[t]{2}{*}{ Groups } & \multirow[t]{2}{*}{ Brands } & \multicolumn{2}{|c|}{ Initial } & \multicolumn{2}{|c|}{ Day 2} & \multicolumn{2}{|c|}{ Day 7} & \multicolumn{2}{|c|}{ Day 30} \\
\hline & & Mean & $S D$ & Mean & $S D$ & Mean & $S D$ & Mean & $S D$ \\
\hline \multirow[t]{4}{*}{$\mathrm{C}$} & $\begin{array}{l}\text { American } \\
\text { orthodontics }\end{array}$ & $2.57^{a}$ & 9.9 & $1.10^{a}$ & 11.6 & $0.64^{a}$ & 15.4 & $0.28^{a}$ & 3.8 \\
\hline & Orthometric & $2.95^{\mathrm{b}}$ & 10.6 & $1.45^{b}$ & 4.2 & $0.94^{b}$ & 14.7 & $0.63^{b}$ & 3.8 \\
\hline & Morelli & $2.98^{b}$ & 8.5 & $0.97^{a}$ & 4.3 & $0.56^{a}$ & 4.4 & $0.38^{c}$ & 2.1 \\
\hline & & $<0.001^{*}$ & & $<0.001^{*}$ & & $<0.001^{*}$ & & $<0.001^{*}$ & \\
\hline \multirow[t]{4}{*}{$E$} & $\begin{array}{l}\text { American } \\
\text { orthodontics }\end{array}$ & $2.70^{a}$ & 8.2 & $1.14^{a}$ & 3.5 & $0.75^{a}$ & 13.4 & $0.27^{a}$ & 3.0 \\
\hline & Orthometric & $3.17^{b}$ & 11.9 & $1.49^{b}$ & 5.4 & $0.94^{a}$ & 16.2 & $0.66^{b}$ & 2.1 \\
\hline & Morelli & $3.12^{b}$ & 10.9 & $1.01^{\mathrm{c}}$ & 5.0 & $0.61^{b}$ & 2.3 & $0.39^{c}$ & 4.6 \\
\hline & & $<0.001^{*}$ & & $<0.001^{*}$ & & $<0.001^{*}$ & & $<0.001^{*}$ & \\
\hline
\end{tabular}

* Statistically significant difference $(p<0.05)$; time points with the same superscript letter do not have statistically significant difference between them

The elastics were stored in artificial saliva at $37^{\circ} \mathrm{C}$, because humidity and higher temperatures influence the force decay of synthetic elastics. ${ }^{3,10}$ The distance of $22 \mathrm{~mm}$ between the rows of pins of the acrylic plates over which the elastics remained stretched was considered, because it simulated the stretching performed to stretch the elastic chain between the first molar and the canine. ${ }^{16}$

Graph 1 shows the behavior of the orthodontic elastic chains during the different intervals of testing. The forces show marked decay during these intervals. This effect was consistent with results reported in the literature, because the decay of the synthetic orthodontic elastic chains results from the elastomeric material used in their production. $5,8,11,12,17,18$ Some authors claim these materials are not ideal for orthodontic mechanics, because they are influenced by time and temperature. ${ }^{1,2}$

The decay of the elastic force that occurred during the first 2 days of testing was more noticeable than during the other periods. The mean decay rate in the control group for this period, considering all three brands, was $58.49 \%$, and in the experimental group, the mean decay was $59.54 \%$. After 30 days of testing, the mean rates of force degradation were 84.98 and $85.49 \%$, respectively. This result was in agreement with previously reported in the literature. ${ }^{19,20}$

The phenomenon of rapid initial force decay of the elastics observed in this study is supported by several studies. ${ }^{1-3,5,10,12,18,21,22}$ This effect occurs unequally: it is more significant in the early stages of activation and less pronounced in the later periods. For this reason, some authors recommend prestretching to change this behavior and keep the force more constant during the use of the elastic., ${ }^{2,7,11,12}$

Comparing the effects of prestretching in the evaluated brands showed a statistically significant difference at the initial time in all of them. Only American Orthodontics showed force levels greater than the control group that remained greater throughout the test period, except at the
30 day time point. This difference in behavior among the brands can be explained by the rearrangement of the molecules of the elastomeric material, which is caused by elastic memory and produces a greater release of force after prestretching.

Although the prestretched elastic chains achieved higher levels of force, they did not demonstrate more regular force decay than the elastics of the control group. The differences among the groups were small relative to the level of decay caused by time; thus the clinical relevance of prestretching can be questioned. ${ }^{5}$

American Orthodontics elastic chains showed a statistically significant difference with or without pre-stretching. This result was in agreement with the literature, because there is no elastomer standardization between brands, which has been previously reported in the literature. ${ }^{3}$

Studies on the decay of the force of orthodontic elastics have included variables that make comparing results difficult. ${ }^{2}$ These variables include the brand, ${ }^{3,6,13,14}$ size, ${ }^{14}$ and color of the elastics, ${ }^{5,15,18}$ the environment in which the elastics were tested such as in vivo or in artificial saliva, distilled water or even in a dry environment, $3,5,7,11,22$ and the amount and method of prestretching, ${ }^{2,8,11,12}$ among others.

\section{CONCLUSION}

The performing and time of prestretching in the brand influenced the force decay of orthodontic elastic chains. Time had a greater influence on elastic decay than brand or prestretching.

\section{REFERENCES}

1. De Genova DC, Ledoux PM, Weinberg R, Shaye R. Force degradation of orthodontic elastomeric chains: a product comparison study. Am J Orthod 1985;87:377-384.

2. Young J, Sandrik JL. The influence of preloading on stress relaxation of orthodontic elastic polymers. Angle Orthod 1979; 49:104-109. 
3. Araújo FBC, Ursi W. Study of force decay generated by synthetic orthodontic elastics. Dental Press Ortodon Ortop Facial 2006; 11:52-61.

4. Arruda PC, Matta ENR, Silva SC. Influence of the Degree of Activation in Plastic Deformation of Orthodontic Elastic Chains. Pesq Bras Odontoped Clin Integr 2011;11:85-90.

5. Baty DL, Storie DJ, Fraunhofer JA. Synthetic elastomeric chains: a literature review. Am J Orthod Dentofac Orthop 1994;10:536-542.

6. Balhoff DA, Shuldberg M, Hagan JL, Ballard RW, Armbruster PC. Force decay of elastomeric chains - a mechanical design and product comparison study. J Orthod 2011;38:40-47.

7. Brantley WA, Salander S, Myers CL, Winders RV. Effects of prestretching on force degradation characteristics of plastic modules. Angle Orthod 1979;49:3743.

8. Andreasen GF, Bishara SE. Comparison of alastik chains with elastics involved with intra-arch molar to molar forces. Angle Orthod 1970;40:151-158.

9. Eliades T, Eliades G, Silikas N, Watts DC. Tensile properties of orthodontic elastomeric chains. Eur J Orthod 2004;26:157-162.

10. Taloumis LJ, Smith TM, Hondrum SO, Lorton L. Force decay and deformation of orthodontic elastomeric ligatures. Am J Orthod 1997;111:1-11

11. Wong AK. Orthodontic elastic materials. Angle Orthod 1976; 46:196-205.

12. Kim KH, Chung CH, Choy K, Lee JS, Vanarsdall RL. Effects of prestretching on force degradation of synthetic elastomeric chains. Am J Orthod Dentofac Orthop 2005;128:477-482.

13. Buchmann N, Senn C, Ball J, Brauchli L. Influence of initial strain on the force decay of currently available elastic chains over time. Angle Orthod 2012 May;82(3):529-535.
14. Josell SD, Leiss JB, Rekow ED. Force degradation in elastomeric chains. Semin Orthod 1997;3:189-197.

15. Martins MM, Mendes AM, Almeida MAO, Goldner MTA, Ramos VF, Guimarães SS. Comparative study of the different colors of elastic bandages. R Dental Press Ortodon Ortop Facial 2006;11:81-90.

16. Yamaguto OT, Vasconcelos MHF. Determination of mesiodistal tooth measures in leucodermic Brazilian individuals with normal occlusion. R Dental Press Ortodon Ortop Facial 2005;10: 99-107.

17. Kersey ML, Glover KE, Heo G, Raboud D, Major PW. A Comparison of dynamic and static testing of latex and nonlatex orthodontic elastics. Angle Orthod 2003;73:181-186.

18. Lu TC, Wang WN, Tarng TH, Chen JW. Force decay of elastomeric chain - a serial study - Part II. Am J Orthod Dentofac Orthop 1993;104:373-377.

19. Kochenborger C, Silva D, Marchioro E, Vargas D, Hahn L. Assessment of force decay in orthodontic elastomeric chains: an in vitro study. Dental Press J Orthod 2011 Nov-Dec;16(6): 93-99.

20. Buchmann N, Senn C, Ball J, Brauchli L. Influence of initial strain on the force decay of currently available elastic chains over time. Angle Orthod 2012 May;82(3):529-535.

21. Halimi A, Benyahia H, Doukkali A, Azeroual MF, Zaoui F. A systematic review of force decay in orthodontic elastomeric power chains. Int Orthod 2012 Sep;10(3):223-240.

22. Halimi A, Azeroual MF, Doukkali A, El Mabrouk K, Zaoui F. Elastomeric chain force decay in artificial saliva: an in vitro study. Int Orthod 2013 Mar;11(1):60-70. 